\title{
The Role of Fetuin-Ain Disease Processes Prevalent in Postmenopausal Women El papel de la fetuina Aen los procesos de enfermedad prevalentes en mujeres posmenopáusicas
}

\author{
Annie A. Bane \& Peter W. Grandjean \\ Baylor University, USA
}

\begin{abstract}
The purpose of this review is to summarize the role of fetuin-A in disease processes prevalent in postmenopausal women and synthesize effective interventions in obtaining healthy fetuin-A levels. A review of databases for articles related to fetuin-A and diseases associated with postmenopausal women was conducted. Articles were limited to full-text access, published in English since 1944. High fetuin-A levels are closely associated with decreased bone mineral density, increased cardiovascular disease risks, impairment of insulin signaling and disruption of adipocyte functioning. Postmenopausal women have increased risk of osteoporosis, cardiovascular disease, insulin-resistance, intra-abdominal fat accumulation and vascular calcification. Low-levels of fetuin-A have been shown to be protective against the latter. The role of fetuin-A is multi-factorial and the mechanisms in which it is involved in each of these processes are vast. The present body of literature is inconsistent in defining high versus low levels of fetuin-A and their association with healthy-matched controls. The diseases associated with high levels of fetuin-A mimic diseases most prevalent in postmenopausal women. In addition, there is no research, to date, exploring fetuin-A levels in postmenopausal women and the associations it may or may not have in related diseases.
\end{abstract}

Key words: fetuin-A; Alpha2-Heremans-Schmid glycoprotein; cardiovascular disease; and elderly, insulin-resistance, intra-abdominal fat, metabolic syndrome, exercise, weight-loss, calorie restriction and postmenopausal.

Resumen. El propósito de esta revisión es sintetizar el papel de la fetuina A en los procesos de enfermedad prevalentes en mujeres posmenopáusicas y resumir las intervenciones efectivas que permiten obtener niveles saludables de fetuina A. Para ello, se revisaron bases de datos con artículos relacionados con fetuina A y las enfermedades asociadas con mujeres posmenopáusicas. La búsqueda de artículos se limitó a aquellos de texto completo publicados en el idioma inglés desde el año 1944. Se encontró que altos niveles de fetuina A están íntimamente relacionados con una reducción de la densidad mineral ósea, un aumento en el riesgo de enfermedad cardiovascular, deterioro de la señalización de la insulina y la alteración del funcionamiento de los adipocitos. Las mujeres posmenopáusicas tienen un mayor riesgo de osteoporosis, enfermedad cardiovascular, resistencia a la insulina, acumulación de grasa intra abdominal y calcificación vascular. Se ha demostrado que niveles bajos de fetuina A son protectores contra esta última condición. El papel de fetuina A es multifactorial y los mecanismos en los que está involucrado en cada uno de estos procesos son muy amplios. El estado actual de la literatura no es consistente en la definición de niveles de fetuina A altos versus bajos y su asociación con controles sanos. Las enfermedades asociadas con altos niveles de fetuina A asemejan las enfermedades más prevalentes en mujeres posmenopáusicas. Además, no existen investigaciones, hasta la fecha, en las que se exploren los niveles de fetuina A en mujeres posmenopáusicas y las asociaciones que puede o no puede tener en las enfermedades relacionadas. Palabras claves: fetuina A, glicoproteína Alpha2-Heremans-Schmid, enfermedad cardiovascular, adulto mayor, resistencia a la insulina, grasa intra abdominal, síndrome metabólico, ejercicio, pérdida de peso, restricción calórica, posmenopausia.

\section{Introduction}

Fetuin-A is a circulating glycoprotein that plays a critical role in bone homeostasis (Price, Toroian, \& Lim, 2009), prevention of vascular calcification(Schäfer etal., 2003), impairment of insulin signaling(Goustin \& Abou-Samra, 2011) and disruption of adipocyte functioning (Rasul, Wagner, \& Kautzky-Willer, 2012). Arguably, the role this liverphosphorylated glycoprotein plays in the prevention and/or amplification of these disease processes seems to be concentration dependent. High levels of fetuin-A have been associated with diseases such as type-2 diabetes mellitus (T2DM), obesity (Schultes, Frick, Ernst, Stefan, \& Fritsche, 2010) and metabolic syndrome (Ix et al., 2006). An increase in myocardial infarction and stroke are also positively correlated with increased fetuin-A blood concentrations (Ix, Wassel \& Kanaya et al., 2008). Low levels, however, have been linked to both detrimental and beneficial health effects (Mehrotra, 2007; Price et al., 2009). Higher mortality rates in patients with chronic kidney disease (CKD) have been closely linked to low circulating fetuin-A (Mehrotra, 2007). Conversely, low levels have a potentially protective effect on arterial calcification in non-CKD patients (Schäfer et al., 2003).

High-levels of fetuin-A seem to be of utmost concem in populations at higher risk of diabetes and cardiovascular disease (CVD). In addition to being at higher risk than pre-menopausal women and age-matched men for diabetes and CVD, postmenopausal women have decreased bone mineral density and increased abdominal fat (Tchernof, Toth, \& Poehlman, 1999). Thenegative health impact that occurs in these women can adversely affect quality and quantity of life. In fact, the risk of CVD, insulin resistance and metabolic syndrome have been shown to rise substantially in postmenopausal women compared to age-matched premenopausal women (Janssen, Powell, Crawford, Lasley, \& SuttonTyrrell, 2008; Lemieux, Prud’homme, Bouchard, Tremblay, \& Després,

Fecha recepción: 30-09-14- Fecha envío revisores: 30-09-14- Fecha de aceptación: 15-11-14 Fecha recepción: 3

annie_bane@baylor.edu
1993; Sutton-Tyrrell et al., 2005). A decrease in ovarian production of estrogen and progesterone has been linked to an increase in insulin resistance (Sathya Bhama, Balaji \& Seethalakshmi, 2012), intra-abdominal fat (Tchernof, Calles-Escandon, Sites, \& Poehlman, 1998) and increased inflammatory markers (Hennige et al., 2008), all of which are associated with metabolic syndrome and/or cardiovascular disease.

Studies determining fetuin-A levels in postmenopausal women are non-existent. High levels have been reported in women with T2DM (Ley et al., 2014), polycystic ovary syndrome (Enli, Fenkci, Fenkci, \& Oztekin, 2013), morbid-obesity (Brix et al., 2010) and obesity (Schultes et al., 2010). Postmenopausal women, particularly, have the highest prevalence of these diseases combined.

The purpose of this review is to summarize the role of fetuin-A in disease processes prevalent in postmenopausal women and synthesize effective interventions in obtaining healthy fetuin-A levels. The role that fetuin-A plays in adipocyte functioning, insulin resistance, inflammation and CVD will be explained. In addition, the physiological alteration that postmenopausal women demonstrate in all of these areas will also be addressed. The importance of this literature review is to initiate a discussion in the importance of fetuin-A's role in menopauserelated diseases and to find interventions that make this population less susceptible to these health complications.

This review of literature included searches of the databases PubMed, Medline, EBSCOhost, Google Scholar and Academic Search Complete for related articles published in English since 1944. Search terms included: fetuin-Aor Alpha2-Heremans-Schmid glycoprotein in combination with: cardiovascular disease and elderly, insulin-resistance, intra-abdominal fat, metabolic syndrome, exercise, weight-loss, calorie restriction and postmenopausal. There are currently no papers (reviews or original research) that look specifically at postmenopausal women and levels of fetuin-A. Due to the lack of research done in the area, a subsequent search was done to provide a review on fetuin-A-related diseases and postmenopausal women. Search terms included: postmenopausal and premenopausal in combination with insulin resistance, cardiovascular 
disease, intra-abdominal fat and calcification. Papers were included that pertained to diseases and/or conditions in which postmenopausal women are most susceptible to. Eighty-nine articles were included in this review, of which, 38 were original research about fetuin-A, 3 were a review of fetuin-A in cardiovascular disease, 1 was a review of measurements of fetuin-A ELISA kits, 22 included a review on the menopausal prevalence of disease and/or hormonal changes, 14 were original research with menopause and insulin resistance or metabolic syndrome, 3 were longitudal studies with menopause and heart disease and 8 were pertaining to menopause and central-fatness and/or intraabdominal fat.

The lack of research regarding fetuin-A and postmenopausal women was very limiting in compiling this review. The lack of research in homogenous populations made it difficult to compare interventions and their effectiveness in lowering fetuin-A. Moreover, the inconsistency of categorized concentrations of low versus high fetuin-A levels made studies hard to compare. In addition, linking diseases associated with menopause and mechanisms of fetuin- $\mathrm{A}$ has not been done. The assortment of literature for menopause and related diseases are vast, yet fetuin-A and menopause is non-existent in current literature.

\section{Physiological Function of Fetuin-A}

Fetuin was first isolated from bovine serum in 1944 (Pedersen, Kai O, 1944). The human form of fetuin is known as Alpha2-HeremansSchmid glycoprotein (AHSG). Structurally, this glycoprotein has binding sites for hydroxyapatite (Heiss et al., 2003) and transforming growth factor-Beta (TGF-Beta) (Demetriou, Binkert, Sukhu, Tenenbaum, \& Dennis, 1996), which help to partially explain fetuin-A's role in bone homeostasis and inflammation. Hydroxyapatite is a major component and essential ingredient for normal bone and teeth development and maintenance. The TGF-Betas are pleiotropic cytokines, which are implicated in a wide variety of cell functions, critically regulating inflammation, extracellular matrix deposition, cell proliferation, differentiation and growth(Dobaczewski, Chen, \& Frangogiannis, 2011) Fetuin-A is rapidly downregulated under acute inflammation and, thus, classified as a negative acute-phase protein (Gangneux et al., 2003) Acute inflammation occurs minutes following injury of tissues when blood flow, permeability and migration of neutrophils are increased (Kumar, Abbas, Fausto, \& Mitchell, 2012). Acute injury can occur after infections, thermal injury (sunburn), splinters and gastric ulcers. Interestingly, in diseases where chronic inflammation is a notable characteristic, as in obesity, CVD or T2DM, fetuin-A is upregulated (Choi et al., 2013; Rasul et al., 2012).

The multi-factorial function of fetuin-A might be further explained by the phosphorylated form of the glycoprotein. Fetuin-A present in blood exists in both active (phosphorylated) and inactive (dephosphorylated) forms. Apart from its role in bone regulation, fetuinA must be phosphorylated to be physiologically active in mammals (Haglund, Ek, \& Ek, 2001). The partially-phosphorylated forms have been shown to inhibit insulin-induced autophosphorylation of the insulin receptor in insect cells (Srinivas et al., 1996). Further, a partiallyphosphorylated form has been identified in humans (Jahnen-Dechent, Trindl, Godovac-Zimmermann, \& Müller-Esterl, 1994). Fetuin-A has been shown to be modified through various means. Modification of fetuin-A is related to N-linked and O-linked glycosylation (Gejyo et al., 1983). This very modification of fetuin-A may help to explain the differing roles fetuin-A plays at different concentrations. Fetuin-A measurements in humans are only taken from the phosphorylated and not modified form. The in vitro modifications of fetuin-A (Schinke et al., 1996) may help explain the plasma-concentration discrepancies in physiological functioning and disease in human plasma.

\section{Concentrations of Fetuin-A}

The average fetuin-A plasma concentration in adults is approximately $300 \mu \mathrm{g} / \mathrm{mL}$ (Haglund et al., 2001). Exact high and low concentration thresholds in relation to disease are yet to be determined. A comparison of studies reporting on conditions and/or diseases addressed in this review and their corresponding fetuin-A levels are reported in Table 1. The highest fetuin-A value measured $(900 \mu \mathrm{g} / \mathrm{mL})$ was in a correlational study evaluating the relationship between visceral fat content and fetuin-A in elderly subjects (73 \pm 3 ) (Ix et al., 2009). Fetuin-A levels in individuals with morbid obesity $(877+318 \mu \mathrm{g} / \mathrm{mL})$,

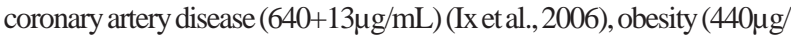
$\mathrm{mL}$ ) (Schultes et al., 2010) and peripheral artery disease and T2DM

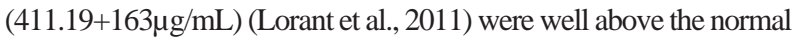
concentrations. Interestingly, all studies included in Table 1 described fetuin-A levels as high, yet the remaining fell below the normal ranges reported in adults. The lowest fetuin-A level reported in a diseased cohort $(230.2+135.9 \mu \mathrm{g} / \mathrm{mL})$ was in a cross-sectional study evaluating arterial stiffness in women (41+10 years of age) (Yang et al., 2011). Other sub-300 $\mu \mathrm{g} / \mathrm{mL}$ levels included studies evaluating myocardial infarction and ischemic stroke (Weikert et al., 2008), hyperinsulimenia (Stefan et al., 2006) and T2DM with and without atherosclerosis (Emoto et al., 2010).

Very few studies examined fetuin-A levels in diseased versus nondiseased states. In fact, only studies examining myocardial infarction and ischemic stroke (Weikert et al., 2008), morbid obesity (Brix et al., 2010) and peripheral artery disease in T2DM(Lorant et al., 2011) were matched with a healthy-controlled counterpart. Interestingly, high levels of fetuin-A were used to describe all diseased/conditions displayed in Table 1.All reported significant differences in concentrations of disease in comparison to healthy-controls.

Perhaps a more definitive concentration of what is considered healthy-normal and observed normal levels of fetuin-A would be better understood. This would help to strengthen the definition of high and low fetuin-Alevels in studies without healthy, non-diseased counterparts.

\section{Endocrinal Changes in Menopause}

The endocrinal changes that occur in postmenopausal women have a steep decline in hormone levels and have been associated with adverse health issues. Particularly, the decrease in ovarian production of estrogen and progesterone has been linked to an increase in insulin resistance (Simpson, Merrill, Hollub, Graham-Lorence, \& Mendelson, 1989), hyperinsulinemia (Tchernof et al., 1998), intra-abdominal fat (Sathya Bhama et al., 2012) and increased inflammatory markers (Lemieux et al., 1993), all of which are associated with metabolic syndrome and/or CVD. Estrogen has also been shown to promote insulin sensitivity and reduce cardiovascular risk by decreasing the visceral fat accumulation and favoring gluteal deposits in a longitudinal study with menopausal

Table

\begin{tabular}{|c|c|c|c|c|c|}
\hline Condition & Ages & Fetuin-A Levels & $\begin{array}{l}\text { Fetuin-ALevels } \\
\text { in Controls }\end{array}$ & Sample Size & Reference \\
\hline $\begin{array}{l}\text { Visceral adiposity in } \\
\text { Elden y }\end{array}$ & $73 \pm 3$ & $900 \mu \mathrm{g} / \mathrm{mL}$ & n/a & $\begin{array}{l}\mathrm{n}=508 \\
\mathrm{men}=132 \\
\text { women=376 }\end{array}$ & $\begin{array}{l}\text { (DeNino et } \\
\text { al., 2001) }\end{array}$ \\
\hline $\begin{array}{l}\text { Coronary Artery } \\
\text { Disease }\end{array}$ & $67 \pm 10$ & $640 \pm 13 \mu \mathrm{g} / \mathrm{mL}$ & n/a & $\begin{array}{l}\mathrm{n}=711 \\
\text { men=583 } \\
\text { women=128 }\end{array}$ & $\begin{array}{l}\text { (Ix et al., } \\
2006)\end{array}$ \\
\hline Obesity & $43.2 \pm 3.2$ & $440 \mu \mathrm{g} / \mathrm{mL}$ & n/a & $\begin{array}{l}\mathrm{n}=14 \\
\text { men=0 } \\
\text { women=14 }\end{array}$ & $\begin{array}{l}\text { (Schultes et } \\
\text { al., 2010) }\end{array}$ \\
\hline $\begin{array}{l}\text { Myocardial } \\
\text { Infartion }\end{array}$ & $54.5 \pm 0.58$ & $253.6 \pm 3.5 \mu \mathrm{g} / \mathrm{mL}$ & $\begin{array}{l}226.9 \pm 1.1 \mu \mathrm{g} / \mathrm{mL} \\
(\mathrm{p}<0.001)\end{array}$ & $\begin{array}{l}\mathrm{n}=227 \\
\mathrm{men}=163 \\
\text { women }=64\end{array}$ & $\begin{array}{l}\text { (Ix et al., } \\
2007 \text { ) }\end{array}$ \\
\hline Is chemic Stroke & $55.9 \pm 0.66$ & $248.7 \pm 4 \mu \mathrm{g} / \mathrm{mL}$ & $\begin{array}{l}226.9 \pm 1.1 \mu \mathrm{g} / \mathrm{mL} \\
(\mathrm{p}<0.001)\end{array}$ & $\begin{array}{l}\mathrm{n}=168 \\
\mathrm{men}=87 \\
\text { women=81 }\end{array}$ & $\begin{array}{l}\text { (Ix et al., } \\
\text { 2007) }\end{array}$ \\
\hline Hyper-insulinemia & $45 \pm 1$ & $269 \pm 11 \mu \mathrm{g} / \mathrm{mL}$ & n/a & $\begin{array}{l}\mathrm{n}=106 \\
\mathrm{men}=50 \\
\text { women=56 }\end{array}$ & $\begin{array}{l}\text { (Stefan et al., } \\
2006 \text { ) }\end{array}$ \\
\hline NAFLD & $50.5 \pm 3.4$ & $420 \mu \mathrm{g} / \mathrm{mL}$ & n/a & $\begin{array}{l}\mathrm{n}=13 \\
\mathrm{men}=11 \\
\text { women }=2\end{array}$ & $\begin{array}{l}\text { (Malin et al., } \\
\text { 2013) }\end{array}$ \\
\hline $\begin{array}{l}\text { T2DM \& } \\
\text { Atherosclerosis }\end{array}$ & $65.8 \pm 6.9$ & $\begin{array}{l}262.6 \pm 56.7 \mu \mathrm{g} / \mathrm{m} \\
\mathrm{L}\end{array}$ & n/a & $\begin{array}{l}\mathrm{n}=416 \\
\text { men=262 } \\
\text { women }=154\end{array}$ & $\begin{array}{l}\text { (Emoto et al., } \\
\text { 2010) }\end{array}$ \\
\hline T2DM & $64.0 \pm 6.2$ & $\begin{array}{l}281.5 \pm 64.6 \mu \mathrm{g} / \mathrm{m} \\
\mathrm{L}\end{array}$ & n/a & $\begin{array}{l}\mathrm{n}=223 \\
\mathrm{men}=134 \\
\text { women }=89\end{array}$ & $\begin{array}{l}\text { (Emoto et al., } \\
2010 \text { ) }\end{array}$ \\
\hline Morbid Obesity & $41 \pm 10$ & $877 \pm 318 \mu \mathrm{g} / \mathrm{mL}$ & $\begin{array}{l}295 \pm 61 \mu \mathrm{g} / \mathrm{mL} \\
(\mathrm{p}<0.001)\end{array}$ & $\begin{array}{l}\mathrm{n}=75 \\
\mathrm{men}=11 \\
\text { women=64 }\end{array}$ & $\begin{array}{l}\text { (Brix et al., } \\
\text { 2010) }\end{array}$ \\
\hline Arterial Stiffness & $45.3 \pm 9.5$ & $\begin{array}{l}230.2 \pm 135.9 \mu \mathrm{g} / \mathrm{m} \\
\mathrm{L}\end{array}$ & n/a & $\begin{array}{l}\mathrm{n}=40 \\
\mathrm{men}=0 \\
\text { women }=40\end{array}$ & $\begin{array}{l}\text { (Yang et al., } \\
\text { 2011) }\end{array}$ \\
\hline $\begin{array}{l}\text { Peripheral Artery } \\
\text { Disease + T2DM }\end{array}$ & $62.2 \pm 4.9$ & $\begin{array}{l}411.19 \pm 163 \mu \mathrm{g} / \mathrm{m} \\
\mathrm{L}\end{array}$ & $\begin{array}{l}356.45 \pm 125.59 \mu \mathrm{g} \\
/ \mathrm{mL}(\mathrm{p}<0.001)\end{array}$ & $\begin{array}{l}\mathrm{n}=107 \\
\text { men=39 } \\
\text { women }=68\end{array}$ & $\begin{array}{l}\text { (Lorant et al., } \\
\text { 2011) }\end{array}$ \\
\hline
\end{tabular}


women (Williams et al., 1996).

In past studies, estrogen therapy has been shown to decrease coronary heart disease(Williams, Adams, \& Klopfenstein, 1990). Recent studies, however, show that hormone replacement treatment has been shown to be ineffective in preventing cardiovascular disease events and may, in fact, increase the risk of stroke and venous thromboembolic events (Main et al., 2013). Hormone replacement therapy is a combination of estrogen and progesterone, however, and not estrogen alone. Fertile women are most protected from cardiovascular disease among adults (Vaccarino et al., 2011). The protective mechanisms that estrogen may have on cardiovascular disease has been shown to attenuate cardiovascular oxidative stress two-fold: first, by preventing generation of reactive oxygen species and second, by scavenging reactive oxygen species in the myocardium and in the vasculature (Arias-Loza, Muehlfelder, \& Pelzer, 2013).

There are no studies, to the authors knowledge, that exist that show correlations between estrogen reduction and changes in fetuin-A levels. An indirect relationship between fetuin-A and estrogen can be inferred due to the increased prevalence of disease in women who experience rapid declines in estrogen due to menopause.

\section{Factors Influencing Fetuin-A}

There are a range of factors influencing fetuin- $\mathrm{A}$ and the roles this glycoprotein may play in various diseases and/or conditions. Fetuin-A has shown to be protective against atherosclerosis at low levels (Schäfer et al., 2003). High levels have been shown to increase various CVD risk factors (Weikert et al., 2008). In addition, insulin resistance (Catalano et al., 2008) and increased intra-abdominal fat (Hennige et al., 2008) have been associated with high levels. In this section, a summary of fetuinA's role in numerous diseases and/or conditions and their paralleled prevalence in postmenopausal women are addressed.

\section{Cardiovascular Disease}

The roles of fetuin-A in cardiovascular disease seem to be contrasting in various pathogenetic mechanisms such as calcification, inflammation and insulin resistance (Weikert et al., 2008). Although low levels of fetuin-A have been shown to have a protective effect against calcification (Schäfer et al., 2003), high levels have been associated with increased risk of cardiovascular disease (Choi et al., 2013). High fetuin-A levels had an approximate 4-fold increase in the risk for myocardial infarction and stroke compared to patients presenting low fetuin-A levels in a 8year follow-up case-cohort study of over 27,000 individuals who averaged 54 years of age (Weikert et al., 2008).

Arterial stiffness has also been associated with high-levels of fetuinA. An association between increased fetuin-A and metabolic syndrome phenotypes and atherogenic lipid profile in 711 non-diabetics with coronary artery disease was demonstrated (Ix et al., 2006). After dividing the patients into quartiles based on levels of fetuin-A, there were also associations with high levels of fetuin-A and increased hypertension, body mass index, inflammatory markers, low-density lipoproteins, triglyceride concentrations and lower high-density lipoproteins. While low fetuin-A levels in younger men have been shown to be associated with decreased cardiovascular markers such as high blood pressure and cholesterol (Hennige et al., 2008) a case cohort study showed that in subjects with low-cholesterol, fetuin-A may be more closely associated with cardiovascular disease. Low levels have also been associated with peripheral artery disease in T2DM (Eraso et al., 2010). The link between fetuin-A and inflammation has also been shown in individuals with carotid arterial stiffness (Mori et al., 2007).

CVD increases substantially after the transition of menopause. Premenopausal women appear to be protected from cardiovascular disease compared with men of the same age, a finding that is similar to insulin resistance in young age-matched males and females (Lejsková, Alušik, Suchánek, Zecová, \& Pitha, 2011). In a nine-year follow-up study, cardiovascular metabolic risk in postmenopausal women was found independent of other cardiovascular disease risk factors (Ramezani Tehrani, Behboudi-Gandevani, Ghanbarian, \& Azizi, 2014). Primary findings of this study revealed women who had experienced menopause compared to those who had not, showed increased serum concentrations of low-density lipoproteins and total cholesterol. It is well-established that the risk of CVD increases as age increases. The occurrence of cardiovascular disease, however, is different in men versus women. In fact, the average onset of cardiovascular disease is delayed ten years in women compared to age and health-risk matched men (Kim \& Reaven, 2013). Statistics from industrialized nations from 2007 show than more women than men die of cardiovascular disease (Rosamond et al., 2007). The acceleration of the development of CVD in women has largely been attributed to adverse health complications due to menopause.

\section{Calcification}

The beneficial effects of low levels of fetuin-A have been shown to inhibit spontaneous calcium phosphate precipitation, acting as a protective mechanism for atherosclerosis and peripheral artery disease (Schäfer et al., 2003). It has been proposed this is due to fetuin-A's involvement in bone homeostasis (Heiss et al., 2003). In a homeostatic bone, less calcium phosphate precipitation means that less calcium is being pulled from the bone, decreasing the calcification of blood vessels. An inverse association with the presence of atherosclerotic calcified plaques and fetuin-A plasma levels in humans has been presented (Emoto et al., 2010). Animal studies have also shown low levels of fetuin-A to be an inhibitor of vascular calcification (Schinke et al., 1996).

In patients with End Stage Renal Disease (ESRD) low levels of fetuin-A were associated with increased cardiovascular and all-cause mortality. The increased vascular calcification in patients with renal disease with low fetuin-A levels is likely to be the mechanism for increased mortality in ESRD patients (Mehrotra, 2007). Hemodialysis has been shown to independently decrease fetuin-A levels (Stout, 1990), possibly decreasing them past the threshold of optimal levels for calcification protection. Individuals with mitral and aortic calcification and stenosis have shown an inverse relationship with fetuin-A (Ix et al., 2007). In this study, levels of fetuin-A were not labeled as «high» or «low». In fact, fetuin-A levels ranged from 590-700 ìg/mL. As seen in Table 1, these levels would be considered high in many cases. These findings may shed light on the importance of fetuin-A in bonehomeostasis to prevent calcification of arteries, especially in diseased states. The level in which bone-homeostasis is optimal has not been studied. In the absence of CKD fetuin-A is associated with plaque stability (Beckman, Ganz, Creager, Ganz, \& Kinlay, 2001; Huang et al., 2001). High levels have been associated with coronary artery calcification in patients with T2DM (Mehrotra et al., 2005). Primary findings were that serum fetuin-A showed significant positive correlations with arterial stiffness measured by brachial-ankle pulse wave velocity, systolic blood pressure, total cholesterol and inflammatory markers. More research is warranted in this area to determine the protective effects in specificpopulations.

The role that fetuin-A plays in cardiovascular diseases is debated in the literature. Though few reviews exist, a thorough examination of the multiple functionality of fetuin-A in the exacerbating and protective factors in the cardiovascular system is examined (Mori, Emoto, \& Inaba, 2012). The conclusion was that fetuin-A had an exacerbating effect on insulin-resistance at high-levels in the blood and a protective effect by inhibiting calcification at low levels. Specific levels, however, were not examined. Limitations, however, are shown to be in the fetuinA assay reliability, which may explain the contradictory findings in the literature (Smith et al., 2010).

\section{Insulin Resistance}

The health impact of insulin resistance are vast and include complications from diseases such as breast cancer, cardiovascular disease and metabolic syndrome (Catalano et al., 2008). The association between Fetuin-A and insulin resistance has been shown in human and animal models (Mathews et al., 2002). Fetuin-A has been found to inhibit insulin receptor tyrosine kinase activity (TKA) in mice (Mathews et al., 2002) and humans (Srinivas et al., 1996). TKA plays an essential 
role in insulin signaling and may help to explain why fetuin-A knockout mice show enhanced glucose sensitivity and clearance, resistance to weight gain (on a high fat diet), decreased serum free-fatty acid levels and decreased body fat compared to controlled mice (on the same high fat diet) (Mathews et al., 2002). Due to this finding, it has been suggested that fetuin-A might be a novel therapeutic target for the treatment of T2DM, obesity and other insulin-resistant conditions.

In humans, high fetuin-A levels were associated with insulin resistance and fat accumulation in the liver in 106 Caucasian subjects without T2DM (Stefan et al., 2006). Individuals with high fetuin-A levels showed impaired glucose tolerance compared to subjects with normal glucose tolerance after adjusting for age, sex and body fat percentage. After 7-days of aerobic exercise (60-min/day at 85\% maximum heart rate), fetuin-A levels decreased substantially (11\%, $\mathrm{P}<0.05)$ and insulin sensitivity was significantly increased $(29 \%, \mathrm{P}<0.05)$ in obese men with non-alcoholic fatty liver disease (NAFLD) (Malin et al., 2013). Similarly, high levels of fetuin-A predict risks of developing T2DM (Rasul et al., 2012) independent of diabetes or glucose levels. A strong association and/or relationship is, therefore, reasonably drawn between fetuin-A and insulin resistance.

The steep decline in estrogen in this population has been closely linked with an increase in insulin resistance. In fact, previously untreated postmenopausal women given oral estrogen therapy improved insulin sensitivity and pancreatic insulin responses to glucose 18-months after treatment (Sutton-Tyrrell et al., 2005). Animal studies have also demonstrated the correlation between insulin resistance and estrogen levels in females. Acessation of female hormone production in mice and rats post an ovariectomy is associated with reduction in insulin sensitivity (Meier \& Garner, 1987; Puah \& Bailey, 1985; Rincon et al., 1996). In a large 9-year follow-up study, glucose-impaired older women ( 71 years of age) displayed higher fetuin-A levels compared to age matchedwomen with normal-glucose tolerance (Ramezani Tehrani et al., 2014). In addition, older glucose-impaired men's fetuin-Alevels did not differ from their matched normal glucose-tolerant counterparts. Therefore, fetuin-A may be a greater influence in the development and/or predictor of T2DM in older women, but not men.

It has been shown that fertile women display the highest insulin sensitivity among adults (Manco et al., 2006). In an age-grouped comparison, non-obese women with a mean age of $67 \pm 6$ years were significantly less insulin sensitive in comparison to non-obese women in other age-grouped cohorts (28-53 years of age) (DeNino et al., 2001). A longitudal comparison (6 years) of metabolic changes in women who experienced menopause with age-matched women who did not concluded that natural menopause was associated with a worsening metabolic profile(Poehlman, Toth, \& Gardner, 1995). In comparison to the women who did not experience menopause, the postmenopausal group had reduced energy expenditure (postmenopausal:-103 $\pm 55 \mathrm{kcal} / \mathrm{d}$ and premenopausal: - $8 \pm 17 \mathrm{kcal} / \mathrm{d}, \mathrm{P}<0.01$ ), accelerated loss of fat-free mass (postmenopausal: $-3.0 \pm 1.1 \mathrm{~kg}$ and postmenopausal: $-0.5 \pm$ $0.5 \mathrm{~kg}$ ) and elevated fasting insulin levels (postmenopausal:- $11 \pm 9$ $\mathrm{pmol} / \mathrm{L}$ and postmenopausal:- $2 \pm 5 \mathrm{pmol} / \mathrm{L}, \mathrm{P}<0.01$ ) (Poehlman et al., 1995). Fetuin-A levels were not measured in this study.

It is therefore apparent that fetuin-A and its role in insulin resistance could serve as an important biomarker in postmenopausal women. The increased incidence of insulin sensitivity in this population is prominent. More research is needed to understand the mechanisms behind the relationship between fetuin-A and insulin resistance.

Hyperinsulinemia is associated with hypertension, obesity, dyslipidemia and glucose intolerance (Modan et al., 1985). In addition, hyperinsulinemia may increase cardiovascular disease risk (Reaven, 1997; Stout, 1990). Postmenopausal women, in particular, have increased development of hyperinsulinemia compared to premenopausal women (Gupta et al., 2008). The hormonal changes associated with menopause decrease progesterone levels markedly (Tchernof et al., 1998) and common treatments for menopause include progesterone (Spark \& Willis, 2012). Progesterone has been shown to independently cause hyperinsulinemia and insulin resistance(Beck, 1969; Kalkhoff, Jacobson,
\& Lemper, 1970). The mechanisms underlying the association between insulin resistance and hyperinsulinemia and cardiovascular disease are still debated. It has been speculated that hyperinsulinemia may require the presence of insulin resistance to increase the risk of cardiovascular disease or may act independently on atherosclerosis (Modan et al., 1985). In a retrospective analysis of the European Group for the Study of Insulin Resistance database, hyperinsulinemia was the best predictor of cardiovascular disease risk score (Manco et al., 2006). In this study, whole-body glucose, insulin concentration, body composition, blood pressure and blood lipid levels were measured in 523 normal and overweight patients. After adjustments for fat freemass, it was determined insulin levels rather than insulin resistance may be a better predictor of CVD risks.

The link between CVD risks, hyperinsulinemia and insulin resistance in postmenopausal women in apparent. The relationship that hyperinsulinemia and insulin resistance have in atherosclerosis needs further investigation. In addition, measuring levels of fetuin-A and their role in these processes could help shed light on the understanding of this glycoprotein and its protective and/or detrimental mechanisms.

\section{Intra-Abdominal Fat}

Fetuin-A, metabolic syndrome and hypoadiponectinemia are all strongly associated with low-grade chronic inflammation and increased intra-abdominal fat (Golden et al., 2007; Matsui et al., 2013; Stefan et al., 2006). Moreover, subclinical inflammation has been shown to be a critical factor in development of atherosclerosis, cardiovascular disease and metabolic syndrome. Metabolic syndrome (Berg et al., 2004; McKinlay, Brambilla, \& Posner, 1992) and abdominal adiposity (DeNino et al., 2001) in women is accelerated during the menopausal transition. Fetuin-A induces inflammatory cytokines related to these conditions by repressing adiponectin production in animals (Hennige et al., 2008). Adiponectin is an anti-inflammatory agent that is produced by fat and is important for the metabolism of glucose and fatty acids (Sathya Bhama et al., 2012). Adiponectin plays an important role in the increased sensitivity of the muscle and liver to insulin. In fact, lowserum adiponectin levels cause intra-abdominal weight gain and thus, are indirectly associated with insulin resistance and metabolic syndrome (Williams et al., 1996).

There are multiple mechanisms behind this association and are only briefly summarized here. The presence of abdominal fat is highly lipolytic, releasing high levels of fatty acids in circulation (Mauriège, Prud'homme, Lemieux, Tremblay, \& Després, 1995). In turn, high levels of free fatty acids in the portal vein, specifically, can increase the secretion of triglyceride-rich lipoproteins and apolipoprotein (apo-B) by the liver (Björntorp, 1990). High levels of free fatty acids are not only associated with increased abdominal fat and hyperinsulinemia, they are also a result of insulin resistance. This in turn effects apo-B and reduces the plasmatic activity of lipoprotein lipase. This can lead to high triglycerides and low high density lipoprotein cholesterol dyslipidemia and the promotion of small, dense LDLs (Lemieux \& Després, 1994). The association with this metabolic profile is closely associated with an array of cardiovascular diseases.

In a study with human monocytes and mice, fetuin-A exerted strong pro-inflammatory effects as well as provoked cytokine expression (Hennige et al., 2008). In this study, mice treated with fetuin-Aincreased adipose tissue inflammatory markers significantly. This increase showed plasma fetuin-A levels and metabolic syndrome may be the result of fetuin-A induced suppression of adiponectin production. This mechanismmay help to explain high levels of fetuin-A in older individuals with increased visceral fat content (Ix et al., 2009). This study was comprised of a majority of female participants (74\%) that were $73 \pm 3$ years of age. Although controls were not used, a strong correlation was demonstrated between abdominal fat and fetuin-A levels of $900 \mathrm{ig} / \mathrm{mL}$, a level 3-times higher than what is considered to be normal.

A worsening metabolic profile was found in women who experienced menopause in comparison to age-matched counterparts who had not 
(Mori et al., 2012). Women who experienced menopause had significant increases in central adiposity. This was determined by a waist-to-hip ratio increase, in comparison to a 6-years baseline (pre: $+0.01 \pm 0.01$ and post: $+0.04 \pm 0.01, \mathrm{p}<0.01$ ) (Poehlman et al., 1995). This may suggest that the association of visceral adipose tissue with age is accelerated with the onset of menopause. It is also noteworthy that body weight did not change significantly among groups (pre: $-1.0 \pm 1$, post: $0.5 \pm 1.1$ ); however, body composition differences were significant (pre: $+2 \pm 0.5 \%$ body fat, pre: $+3.7 \pm 0.5 \%$ body fat, $\mathrm{p}<0.01$ ). Moreover, women who experienced menopause lost more fat-free mass compared to age-matched women who did not experience menopause $(-0.5 \pm 0.5$, post: $-3.0 \pm 1.1, \mathrm{p}<0.01)$ (Poehlman et al., 1995). These changes may help mitigate the worsening cardiovascular and metabolic risk profile associated with menopause.

The accentuated storage of excess fat in the abdominal area may augment the development of hepatic insulin resistance (Williams et al., 1996). Adverse health concerns associated with central obesity in a correlational study of 455 normoglycemic normotensive postmenopausal women included a positive correlation with age, BMI, fasting plasma glucose, triglycerides, insulin, blood pressure, homeostatic model assessment of insulin resistance (HOMA-IR), aortic and peripheral pulse wave velocity (Park et al., 2010). In these same women, a negative correlation with central obesity and high-density lipoprotein levels and adiponectin was shown (Park et al., 2010).

In two studies investigating the endocrine characteristics (Després \& Marette, 1994) and metabolic complications (Lord \& Wilkin, 2002) in polycystic ovary syndrome phenotypes, central distribution and accumulation of adipose tissue and insulin resistance was shown to be important components in metabolic abnormalities strongly correlated with coronary heart disease. When comparing two patterns of fatdistribution in the abdominal region versus the gluteo-femoral region, abdominal region was only associated with dyslipidemia and insulin resistance (Després \& Marette, 1994). The alteration of hormonal balance contributes to an increased visceral fat deposition (Kalish, BarrettConnor, Laughlin, \& Gulanski, 2003) which in turn is associated with insulin resistance and increased cardiovascular disease in postmenopausal women (Kahn et al., 2001). Deposition of intra-abdominal fat through the menopausal transition has also been associated with alterations of the lipoprotein profile and carbohydrate metabolism (Costrini \& Kalkhoff, 1971; Schäfer et al., 2003).

Through the menopausal transition, androgenic status increases in conjunction with abdominal fat deposition (Mesch et al., 2008). This study demonstrated this effect by the significant negative correlation found between waist circumference and sex hormone binging globulin (SHBG) and a positive correlation between waist circumference and the free androgen index. In addition, metabolic syndrome, which is highly correlated with cardiovascular disease, has shown a strong correlation between abdominal obesity and accelerated incidence of metabolic syndrome (Janssen et al., 2008).

It can be speculated that increased CVD risk is due to a rise in androgenic effects associated with adipose tissue redistribution in postmenopausal women. Fetuin-A and its role in suppressing adiponectin has been demonstrated. Adiponectin has been directly linked to increased intra-abdominal fat. The link between fetuin-A levels, suppression of adiponectin and accumulation of central-adiposity through the menopausal transition has yet to be studied.

\section{Interventions Affecting Fetuin-A Levels}

Although studies are limited in their direct effect on altering fetuinA levels, few interventions have been shown to be effective. Decreasing fetuin-A levels through weight loss (Brix et al., 2010), dietary intervention (Choi et al., 2013) and/or exercise (Jenkins, McKenzie, Hagberg, \& Witkowski, 2011) has been positively correlated with decreased insulin resistance, increased glucose tolerance and markers of cardiovascular disease risks. In high-risk populations, such as postmenopausal women, it is crucial to examine these interventions and their association with decreased risk of susceptible diseases.

\section{Weight Loss}

Significant weight loss has been shown to affect fetuin-A levels. Sixteen-months post-gastric bypass surgery and dramatic weight loss, significant drops in fetuin-A levels were demonstrated in 75 morbidly obese patients ( $\mathrm{n}=65$ women) (Lorant et al., 2011). All patients were free of cardiovascular disease, but not insulin resistance. Before gastric bypass surgery intervention, fetuin-A concentrations were elevated in patients that were morbidly obese compared with non-obese controls. The fetuin-A levels in the morbidly obese patients were comparable with the accumulation of visceral adipose tissue in older persons (Ix et al., 2009) $[900 \mu \mathrm{g} / \mathrm{ml}]$ indicating a possible upper limit for fetuin-A levels and the association with disease.

The link with obesity and diabetes is known. Bariatric surgery has been shown to induce resolution of T2DM in $70-80 \%$ of those undergoing the surgery (Buchwald et al., 2009; Kopp et al., 2003). The association between insulin resistance and fetuin-A has been made clear. In fact, subjects with high fetuin-A levels have an increased risk of incident diabetes (Stefan et al., 2008). Increased ageincreases theincidence of diabetes in individuals with high fetuin-A plasma levels (Ix et al., 2009).

Limited studies in this area show that morbidly obese individuals have increased fetuin-A levels compared to normal-weight controls and levels mimic older individuals that are not-obese (Brix et al., 2010). It is commonly known that obesity is highly associated with low-grade chronic inflammation (Gangneux et al., 2003). The mechanisms behind the decrease in weight and the association with fetuin-A and inflammation are unknown, but can be speculated. Further research is needed to investigate this relationship.

\section{Dietary Interventions}

Calorie restriction over 12-weeks in overweight sedentary women with T2DM significantly decreased fetuin-A levels (-133.3ìg/mL, $\mathrm{p}=0.038$ ) (Choi et al., 2013). Primary findings also indicated a decrease in apo-B $(-0.08 \mathrm{~g} / \mathrm{l}, \mathrm{p}=0.007)$ and low-density lipoproteins $(-0.3 \mathrm{mM}$, $\mathrm{p}=0.47$ ) demonstrating a decrease in cardiovascular disease risks. Concerning postmenopausal women, a decrease in apo-B may help to lessen the degree of intra-abdominal fat accumulation and low-grade inflammation. Also in relation to favorable decreases in abdominal fat, adiponectin was increased 2.96\% ( $\mathrm{p}=0.021)$. A 9-month longitudinal study showed that by reducing total dietary fat and intake of saturated fat, subsequent decreases in mean liver fat and fetuin-A plasma levels were demonstrated in healthy Caucasian individuals without diabetes (Stefan et al., 2006). This result was independent of significant decreases in body fat. A correlational analysis of the data collected also showed a strong association between fat on the liver and increases in fetuin- $\mathrm{A}$ release.

The role that calorie restriction plays in decreasing fetuin-A may be independent of weight loss. Many postmenopausal women are not obese, yet have increased intra-abdominal fat (DeNino et al., 2001), insulin resistance and CVD (Manco et al., 2006) compared to their premenopausal years. It is important for future research studies to observe fetuin-A changes due to dietary intervention in obese and nonobese women. Perhaps the link between inflammation and fetuin-A could be better understood in this differentiation.

\section{Exercise}

Several exercise-centered studies have shown promising improvements in fetuin-A plasma content. Overall, fetuin-A is higher in sedentary individuals, absent of disease, in comparison to those who were highly active (Jenkins et al., 2011). Another primary finding in this study was fetuin-A was $20 \%$ higher in low-active men compared to age-matched high-active men and inversely related to VO2 maximum oxygen uptake.

In middle aged men withnon-alcoholic fatty liver disease(NAFLD), 7-days of aerobic exercise at $85 \%$ maximum heart rate for 60 minutes dramatically decreased fetuin-A levels, insulin resistance (29\%) and 
glucose tolerance (13\%) (Malin et al., 2013). These results were independent of weight loss. Moreover, fourteen nondiabetic, obese women did not show changes in fetuin-A levels after 6-weeks of selfregulated aerobic exercise performed 3-days per week despite a decrease in body fat content and waist circumference (Schultes et al., 2010) While weight loss studies may show the relationship between fetuin-A and inflammation, the improvement with exercise may show the role that fetuin-A plays in skeletal muscle insulin-resistance.

In a three-month combined aerobic and resistance training program, individuals did not alter their levels of fetuin-A(Yang et al., 2011). The exercise protocol consisted of 45-minutes of aerobic exercise at 60-75\% of age-predicted maximum heart rate and 20-minutes of resistance training five-days per week. Arterial stiffness was improved, but fetuin-A was unchanged. This may indicate that an alteration in fetuin-A levels with an exercise intervention maybe dose and intensity-responsive rather than weight-loss dependent. More research is needed in this area.

Exercise and healthy dieting has been proven to be beneficial in preventing or attenuating all of the previously mentioned diseases. Weight loss has often been a determinant for exercise and diet effectiveness in healthy and diseased-individuals. The focus solely on weight loss might have more negative impact than was once thought. In fact, fragility, after the age of 65 leads to increased mortality in comparison to obesity (Cao, Moineddin, Urquia, Razak, \& Ray, 2014). It is therefore apparent that other biomarkers in preventing and treating postmenopausal conditions need to be established. The impact of formulating a nutrition and or exercise intervention that decreases fetuin-A levels has important implications in individuals more susceptible to these diseases and/or conditions, such as postmenopausal women.

\section{Future Studies}

Future studies are needed to determine the levels and types of populations in which fetuin-A crosses the threshold from being protective against calcification to being a precursor to increased insulin resistance, inflammation and cardiovascular events. A standardization of fetuin-A assays is needed in order to validate findings. This would help further explain differentiating concentrations of fetuin-A and help to confirm if low levels are indeed protective and high levels are detrimental. In addition, establishing normal, low and high levels of fetuin-A is warranted to justify claims of high and low levels in the literature.

Second, fetuin-A levels before and after menopause need to be determined to further explain the increased risk of disease in postmenopausal women. Postmenopausal women are a very vulnerablepopulation to CVD, T2DM and metabolic syndrome. Understanding the levels of fetuin-A in this population and drawing links between the possible association with disease would be pivotal for research in this area and possible interventions to achieve optimal levels. Once optimal levels are established in various populations and diseases, fetuin-A could be a target blood marker in clinical settings.

Last, randomized controlled-trials in exercise and nutrition interventions need to be studied to infer causal relationships with fetuinA and previously mentioned disease-processes. Most interventional studies pertaining to exercise and fetuin-A are cross-sectional. More controlled studies with interventions varying in exercise duration and intensity would help to clear up any discrepancies with exercise and the possible beneficial effects on fetuin-A levels. In addition, frequency and intensity-specific exercise protocol need to be compared in their alterations of fetuin-A in diseased and healthy populations. Studies of this nature would also help to establish better or more precise normative, healthy levels of plasma fetuin-A concentrations.

\section{Conclusions}

It is apparent that postmenopausal women are at increased risk for insulin resistance, hyperinsulinemia, metabolic syndrome and CVD. The potential role that fetuin-A plays in intra-abdominal redistribution, insulin resistance, inflammatory markers and CVD is vast and not fully understood. The positive correlation with age and negative correlation with physical activity that has been displayed with levels of fetuin-A makes it a novel plasma target for disease prevention and/or treatment. In postmenopausal women who are susceptible to insulin resistance, metabolic syndrome and CVD, this biomarker may shed light on effective interventions. It is apparent that more research is needed in order to standardize target fetuin-A levels in postmenopausal women.

The protective and exacerbating effects of fetuin-A seem to be dose-respondent and further research is needed to fully understand this mechanism. Due to the strong association with increased fetuin-A in older women, inactive individuals, obese patients and individuals with insulin resistance, NAFLD and T2DM, it is apparent that further investigation would help explain the mechanisms behind the role of fetuin-A. In addition, establishing parameters of low and high fetuin-A levels may help to make this glycoprotein applicable in the clinical setting.

Exercise and dietary interventions have been shown to lower fetuinA levels. Some of the same interventions are currently used to decrease cardiometabolic risks and improve health in men and women. The role that fetuin-A plays in ameliorating risks and/or improving health has yet to be fully elucidated. This is particularly true in postmenopausal women.

\section{References}

Arias-Loza, P.-A., Muehlfelder, M., \& Pelzer, T. (2013). Estrogen and estrogen receptors in cardiovascular oxidative stress. Pflügers Archiv: European Journal OfPhysiology, 465(5), 739-746. doi:10.1007/s00424-013-1247-7

Beck, P. (1969). Progestin enhancement of the plasma insulin response to glucose in Rhesus monkeys. Diabetes, 18(3), 146-152.

Beckman, J. A., Ganz, J., Creager, M. A., Ganz, P., \& Kinlay, S. (2001). Relationship of clinical presentation and calcification of culprit coronary artery stenoses. Arteriosclerosis, Thrombosis, And Vascular Biology, 21(10), 1618-1622.

Berg, G., Mesch, V., Boero, L., Sayegh, F., Prada, M., Royer, M., . . . Benencia, H. (2004).Lipidand lipoprotein profileinmenopausal transition. Effects of hormones, age and fat distribution. Hormone And Metabolic Research = Hormon- Und Stoffwechselforschung = Hormones Et Métabolisme, 36(4), 215-220.

Björntorp, P. (1990). «Portal» adipose tissue as a generator of risk factors for cardiovascular disease and diabetes. Arteriosclerosis (Dallas, Tex.), 10(4), 493-496.

Brix, J. M., Stingl, H., Höllerl, F., Schernthaner, G. H., Kopp, H.-P., \& Schernthaner, G (2010). Elevated Fetuin-A concentrations in morbid obesity decrease after dramatic weight loss. The Journal OfClinical Endocrinology And Metabolism, 95(11), 4877-4881. doi:10.1210/jc.2010-0148

Buchwald, H., Estok, R., Fahrbach, K., Banel, D., Jensen, M. D., Pories, W. J., . . . Sledge, I. (2009). Weight and type 2 diabetes after bariatric surgery: systematic review and meta-analysis. The American Journal Of Medicine, 122(3), 248256.e5. doi:10.1016/j.amjmed.2008.09.041

Cao, S., Moineddin, R., Urquia, M. L., Razak, F., \& Ray, J. G. (2014). Jshapedness: an often missed, often miscalculated relation: the example of weight and mortality. Journal Of Epidemiology And Community Health.

Catalano, D., Trovato, G. M., Spadaro, D., Martines, G. F., Garufi, G., Tonzuso, A., .. Sciacchitano, S. G. (2008). Insulin resistance in postmenopausal women: concurrent effects of hormone replacement therapy and coffee. Climacteric: The Journal Of The International Menopause Society, 11(5), 373-382. doi:10.1080/ 13697130802348728

Choi, K. M., Han, K. A., Ahn, H. J., Lee, S. Y., Hwang, S. Y., Kim, B.-H., .. Min, K.W.(2013). The effects of caloric restriction on fetuin-Aand cardiovascular risk factors in rats and humans: a randomized controlled trial. Clinical Endocrinology, 79(3), 356-363. doi:10.1111/cen.12076

Costrini, N. V., \& Kalkhoff, R. K. (1971). Relative effects of pregnancy, estradiol, and progesterone on plasma insulin and pancreatic islet insulin secretion. The Journal Of Clinical Investigation, 50(5), 992-999.

Demetriou, M., Binkert, C., Sukhu, B., Tenenbaum, H. C., \& Dennis, J. W. (1996). Fetuin/alpha2-HS glycoprotein is a transforming growth factor-beta type II receptor mimic and cytokine antagonist. The Journal Of Biological Chemistry, 271(22), 12755-12761.

DeNino, W. F., Tchernof, A., Dionne, I. J., Toth, M. J., Ades, P. A., Sites, C. K., \& Poehlman, E.T.(2001). Contribution of abdominal adiposity to age-related differences in insulin sensitivity and plasma lipids in healthy nonobese women. Diabetes Care, 24(5), 925-932.

Després, J. P., \& Marette, A. (1994). Relation of components of insulin resistance syndrome to coronary disease risk. Current Opinion In Lipidology, 5(4), 274 289. 
Dobaczewski, M., Chen, W., \& Frangogiannis, N. G. (2011). Transforming growth factor (TGF)-â signaling in cardiac remodeling. Journal Of Molecular And Cellular Cardiology,51(4), 600-606. doi:10.1016/j.yjmcc.2010.10.033

Emoto, M., Mori, K., Lee, E., Kawano, N., Yamazaki, Y., Tsuchikura, S., .. Nishizawa,Y.(2010). Fetuin-A and atherosclerotic calcified plaque in patients with type 2 diabetes mellitus. Metabolism: Clinical And Experimental,59(6), 873-878. doi:10.1016/j.metabol.2009.10.005

Enli, Y., Fenkci, S. M., Fenkci, V., \& Oztekin, O. (2013). Serum Fetuin-A levels, insulin resistance and oxidative stress in women with polycystic ovary syndrome. Gynecological Endocrinology: The Official Journal Of The Internationa Society Of Gynecological Endocrinology, 29(12), 1036-1039. doi:10.3109/ 09513590.2013 .829442

Eraso, L. H., Ginwala, N., Qasim, A. N., Mehta, N. N., Dlugash, R., Kapoor, S., ... Reilly, M. P. (2010). Association of lower plasma fetuin-a levels with peripheral arterial disease in type 2 diabetes. Diabetes Care, 33(2), 408-410. doi:10.2337/dc09-1541

Gangneux, C., Daveau, M., Hiron, M., Derambure, C., Papaconstantinou, J., \& Salier, J.-P. (2003). The inflammation induced down regulation of plasma Fetuin A (á2HS Glycoprotein) in liver results from the loss of interaction between long C/EBP isoforms at two neighbouring binding sites. Nucleic Acids Research,31(20), 5957-5970. doi:10.1093/nar/gkg788

Gejyo, F., Chang, J. L., Bürgi, W., Schmid, K., Offner, G D., Troxler, R. F., .. Vliegenthart, J. F. (1983). Characterization of the B-chain of human plasma alpha 2HS-glycoprotein. The complete amino acid sequence and primary structure of its heteroglycan. The Journal Of Biological Chemistry, 258(8), 4966-4971.

Golden, S. H., Dobs, A. S., Vaidya, D., Szklo, M., Gapstur, S., Kopp, P., .. Ouyang, P. (2007). Endogenous sex hormones and glucose tolerance status in postmenopausal women. The Journal Of Clinical Endocrinology And Metabolism, 92(4), 1289-1295.

Goustin, A.-S., \& Abou-Samra, A. B. (2011). The «thrifty» gene encoding Ahsg Fetuin-A meets the insulin receptor: Insights into the mechanism of insulin resistance. Cellular Signalling, 23(6), 980-990. doi:10.1016/ j.cellsig.2010.11.003

Gupta, P., Harte, A., Sturdee, D. W., Sharma, A., Barnett, A. H., Kumar, S., \& McTernan, P. G. (2008). Effects of menopausal status on circulating calcitonin gene-related peptide and adipokines: implications for insulin resistance and cardiovascular risks. Climacteric: The Journal Of The International Menopause Society, 11(5), 364-372. doi:10.1080/13697130802378493

Haglund,A. C., Ek, B., \& Ek, P. (2001). Phosphorylation of human plasma alpha2 Heremans-Schmid glycoprotein (human fetuin) in vivo. The Biochemical Journal, 357(Pt 2), 437-445.

Heiss, A., DuChesne, A., Denecke, B., Grötzinger, J., Yamamoto, K., Renné, T., \& Jahnen-Dechent,W. (2003). Structural basis of calcification inhibition by alpha 2-HS glycoprotein/fetuin-A. Formation of colloidal calciprotein particles. The Journal OfBiological Chemistry, 278(15), 13333-13341.

Hennige, A. M., Staiger, H., Wicke, C., Machicao, F., Fritsche, A., Häring, H.-U., \& Stefan, N. (2008). Fetuin-A Induces Cytokine Expression and Suppresses Adiponectin Production. PLoS ONE, 3(3), e1765. doi:10.1371/ journal.pone.0001765

Huang, H., Virmani, R., Younis, H., Burke, A. P., Kamm, R. D., \& Lee, R. T. (2001). Theimpact of calcification on the biomechanical stability of atherosclerotic plaques. Circulation, 103(8), 1051-1056.

Ix, J. H., Chertow, G. M., Shlipak, M. G., Brandenburg, V. M., Ketteler, M., \& Whooley, M.A.(2007).Association of Fetuin-AWithMitralAnnularCalcification andAortic Stenosis Among Persons With Coronary Heart Disease Data From the Heart and Soul Study. Circulation, 115(19), 2533-2539. doi:10.1161/ CIRCULATIONAHA.106.682450

Ix, J. H., Shlipak, M. G., Brandenburg, V. M., Ali, S., Ketteler, M., \& Whooley, M. A. (2006). Association Between Human Fetuin-A and the Metabolic Syndrome Data From the Heart and Soul Study. Circulation, 113(14), 1760 1767. doi:10.1161/CIRCULATIONAHA.105.588723

Ix, J. H., Wassel, C. L., Chertow, G. M., Koster, A., Johnson, K. C., Tylavsky, F. A., ... Shlipak, M. G. (2009). Fetuin-A and change in body composition in older persons. The Journal Of Clinical Endocrinology And Metabolism, 94(11), 4492-4498. doi:10.1210/jc.2009-0916

Ix, Wassel, Kanaya, \& et al. (2008). FEtuin-a and incident diabetes mellitus in older persons. JAMA, 300(2), 182-188. doi:10.1001/jama.300.2.182

Jahnen-Dechent, W., Trindl, A., Godovac-Zimmermann, J., \& Müller-Esterl, W. (1994). Posttranslational processing of human alpha 2-HS glycoprotein (human fetuin). Evidence for the production of a phosphorylated single-chain form by hepatoma cells. European Journal Of Biochemistry/FEBS, 226(1), 59-69.

Janssen, I., Powell, L., Crawford, S., Lasley, L., \& Sutton-Tyrrell,, K. (2008) Menopause and the metabolic syndrome: The study of women's health across the nation. Archives of Internal Medicine, 168(14), 1568-1575. doi:10.1001/ archinte.168.14.1568
Jenkins, N. T., McKenzie, J.A., Hagberg, J. M., \& Witkowski, S. (2011). Plasma fetuin-A concentrations in young and older high- and low-active men. Metabolism: Clinical And Experimental, 60(2), 265-271. doi:10.1016/ j.metabol.2010.01.026

Kahn, S. E., Prigeon, R. L., Schwartz, R. S., Fujimoto, W. Y., Knopp, R. H., Brunzell, J. D., \& Porte, D., Jr. (2001). Obesity, body fat distribution, insulin sensitivity and Islet beta-cell function as explanations for metabolic diversity. The Journal Of Nutrition, 131(2), 354S-360S.

Kalish, G. M., Barrett-Connor, E., Laughlin, G. A., \& Gulanski, B. I. (2003). Association of endogenous sex hormones and insulin resistance among postmenopausal women: results from the Postmenopausal Estrogen/Progestin Intervention Trial. The Journal OfClinical Endocrinology And Metabolism, 88(4), 1646-1652.

Kalkhoff, R. K., Jacobson, M., \& Lemper, D. (1970). Progesterone, pregnancy and the augmented plasma insulin response. The Journal OfClinical Endocrinology And Metabolism, 31(1), 24-28.

Kim, S.H., \& Reaven, G (2013). Sex differences ininsulinresistanceand cardiovascular disease risk. The Journal OfClinical Endocrinology And Metabolism, 98(11), E1716-E1721. doi:10.1210/jc.2013-1166

Kopp, H. P., Kopp, C. W., Festa, A., Krzyzanowska, K., Kriwanek, S., Minar, E., .. Schernthaner, G (2003). Impact of weight loss on inflammatory proteins and their association with the insulin resistance syndrome in morbidly obese patients. Arteriosclerosis, Thrombosis, And Vascular Biology, 23(6), 10421047.

Kumar, V., Abbas, A. K., Fausto, N., \& Mitchell, R. (2012). Robbins Basic Pathology. Elsevier Health Sciences.

Lejsková, M.,Alušik, S., Suchánek, M., Zecová, S., \& Pitha, J.(2011). Menopause: clustering of metabolic syndrome components and population changes in insulin resistance. Climacteric: The Journal Of The International Menopause Society, 14(1), 83-91. doi:10.3109/13697131003692745

Lemieux, S., \& Després, J. P. (1994). Metabolic complications of visceral obesity: contribution to the aetiology of type 2 diabetes and implications for prevention and treatment. Diabète \& Métabolisme, 20(4), 375-393.

Lemieux, S., Prud'homme, D., Bouchard, C., Tremblay, A., \& Després, J. P. (1993). Sex differences in the relation of visceral adipose tissue accumulation to total body fatness. The American Journal of Clinical Nutrition, 58(4), 463467.

Ley, S. H., Sun, Q., Jimenez, M. C., Rexrode, K. M., Manson, J. E., Jensen, M. K., ... Hu, F. B. (2014). Association between alcohol consumption and plasma fetuin-A and its contribution to incident type 2 diabetes in women. Diabetologia, 57(1), 93-101. doi:10.1007/s00125-013-3077-8

Lorant, D. P., Grujicic, M., Hoebaus, C., Brix, J.-M., Hoellerl, F., Schernthaner, G. ... Schernthaner, G.-H. (2011). Fetuin-A levels are increased in patients with type 2 diabetes and peripheral arterial disease. Diabetes Care,34(1), 156-161. doi:10.2337/dc10-0788

Lord, J., \& Wilkin, T. (2002). Polycystic ovary syndrome and fat distribution: the central issue? Human Fertility (Cambridge, England), 5(2), 67-71.

Main, C., Knight, B., Moxham, T., Gabriel Sanchez, R., Sanchez Gomez, L. M., Roquéi Figuls, M., \& Bonfill Cosp, X. (2013). Hormone therapy for preventing cardiovascular disease in post-menopausal women. The Cochrane Database OfSystematic Reviews, 4, CD002229. doi:10.1002/14651858.CD002229.pub3

Malin, S. K., Mulya, A., Fealy, C. E., Haus, J. M., Pagadala, M. R., Scelsi, A. R., ... Kirwan, J. P. (2013). Fetuin-A is linked to improved glucose tolerance after short-term exercise training in nonalcoholic fatty liver disease. Journal Of Applied Physiology (Bethesda, Md.: 1985), 115(7), 988-994. doi:10.1152/ japplphysiol.00237.2013

Manco, M., Nolfe, G., Calvani, M., Natali, A., Nolan, J., Ferrannini, E., \& Mingrone, G. (2006). Menopause, insulin resistance, and risk factors for cardiovascular disease. Menopause (New York, N.Y.), 13(5), 809-817.

Mathews, S. T., Singh, G. P., Ranalletta, M., Cintron, V. J., Qiang, X., Goustin, A. S., ... Grunberger, G. (2002). Improved insulin sensitivity and resistance to weight gain in mice null for the Ahsg gene. Diabetes, 51(8), 2450-2458.

Matsui, S., Yasui, T., Tani, A., Kunimi, K., Uemura, H., Yamamoto, S., . . Irahara, M. (2013). Associations of estrogen and testosterone with insulin resistance in pre- and postmenopausal women with and without hormone therapy. International Journal Of Endocrinology And Metabolism, 11(2), 65-70. doi:10.5812/ijem.5333

Mauriège, P., Prud'homme, D., Lemieux, S., Tremblay, A., \& Després, J. P. (1995). Regional differences in adipose tissue lipolysis from lean and obese women: existence of postreceptor alterations. The American Journal Of Physiology, 269(2Pt1), E341-E350.

McKinlay, S. M., Brambilla, D. J., \& Posner, J. G. (1992). The normal menopause transition. Maturitas, 14(2), 103-115. doi:10.1016/0378-5122(92)90003-M

Mehrotra, R. (2007). Emerging role for fetuin-A as contributor to morbidity and mortality in chronic kidney disease. Kidney International, 72(2), 137-140.

Mehrotra, R., Westenfeld, R., Christenson, P., Budoff, M., Ipp, E., Takasu, J. ... 
Adler, S. (2005). Serum fetuin-A in nondialyzed patients with diabetic nephropathy: relationship with coronary artery calcification. Kidney International, 67(3), 1070-1077.

Meier, D. A., \& Garner, C. W. (1987). Estradiol stimulation of glucose transport in rat uterus. Endocrinology, 121(4), 1366-1374.

Mesch, V. R., Siseles, N. O., Maidana, P. N., Boero, L. E., Sayegh, F., Prada, M. ... Berg, G.A. (2008). Androgens in relationship to cardiovascular risk factors in the menopausal transition. Climacteric: The Journal Of The International Menopause Society, 11(6), 509-517. doi:10.1080/13697130802416640

Modan, M., Halkin, H., Almog, S., Lusky, A., Eshkol, A., Shefi, M., . . Fuchs, Z. (1985). Hyperinsulinemia. A link between hypertension obesity and glucose intolerance. The Journal OfClinical Investigation, 75(3), 809-817.

Mori, K., Emoto, M., Araki, T., Yokoyama, H., Teramura, M., Lee, E., ... Nishizawa, Y.(2007). Association of serum fetuin-Awith carotid arterial stiffness. Clinical Endocrinology, 66(2), 246-250.

Mori, K., Emoto, M., \& Inaba, M. (2012). Fetuin-A and the cardiovascular system. Advances In Clinical Chemistry, 56, 175-195.

Park, J. S., Nam, J. S., Cho, M. H., Yoo, J. S., Ahn, C. W., Jee, S. H., ... Lee, H. C. (2010). Insulin resistance independently influences arterial stiffness in normoglycemic normotensive postmenopausal women. Menopause(New York, N.Y.), 17(4), 779-784. doi:10.1097/gme.0b013e3181cd3d60

Pedersen, Kai O. (1944). Fetuin, a New Globulin Isolated from Serum. Nature, 154(575). Retrieved from http://www.nature.com/nature/journal/v154/n3914/ abs/154575a0.html

Poehlman, E. T., Toth, M. J., \& Gardner, A. W. (1995). Changes in energy balance and body composition at menopause: a controlled longitudinal study. Annals Of Internal Medicine, 123(9), 673-675.

Price, P.A., Toroian, D., \& Lim, J. E. (2009). Mineralization by Inhibitor Exclusion THE CALCIFICATION OF COLLAGEN WITH FETUIN. Journal of Biological Chemistry, 284(25), 17092-17101. doi:10.1074/jbc.M109.007013

Puah, J.A., \& Bailey, C. J.(1985). Effect of ovarian hormones on glucose metabolism in mouse soleus muscle. Endocrinology, 117(4), 1336-1340.

Ramezani Tehrani, F., Behboudi-Gandevani, S., Ghanbarian,A., \&Azizi, F. (2014) Effect of menopause on cardiovascular disease and its risk factors: a 9-year follow-up study. Climacteric: The Journal Of The International Menopause Society, 17(2), 164-172. doi:10.3109/13697137.2013.828197

Rasul, S., Wagner, L., \& Kautzky-Willer,A. (2012). Fetuin-A and angiopoietins in obesity and type 2 diabetes mellitus. Endocrine, 42(3), 496-505. doi:10.1007/ s12020-012-9754-4

Reaven, G. M. (1997). Banting Lecture 1988. Role of insulin resistance in human disease. 1988. Nutrition (Burbank, Los Angeles County, Calif.), 13(1), 65.

Rincon, J., Holmäng, A., Wahlström, E. O., Lönnroth, P., Björntorp, P., Zierath, J.R., \&Wallberg-Henriksson, H. (1996). Mechanisms behind insulin resistance in rat skeletal muscle after oophorectomy and additional testosterone treatment. Diabetes, 45(5), 615-621.

Rosamond, W., Flegal, K., Friday, G., Furie, K., Go, A., Greenlund, K., ... Hong, Y. (2007). Heart disease and stroke statistics - 2007 update: a report from the American Heart Association Statistics Committee and Stroke Statistics Subcommittee. Circulation, 115(5), e69-e171.

Sathya Bhama, C. V., Balaji, S., \& Seethalakshmi,A. (2012). Analysis of the degree of insulin resistance in post menopausal women by using skin temperature measurements and fasting insulin and fasting glucose levels: a case control study. Journal Of Clinical And Diagnostic Research: JCDR, 6(10), 1644 1647. doi:10.7860/JCDR/2012/4377.2646

Schäfer, C., Heiss, A., Schwarz, A., Westenfeld, R., Ketteler, M., Floege, J., .. Jahnen-Dechent, W. (2003). The serum protein á2-Heremans-Schmid glycoprotein/fetuin-A is a systemically acting inhibitor of ectopic calcification. Journal of Clinical Investigation, 112(3), 357-366. doi:10.1172/JCI17202

Schinke, T., Amendt, C., Trindl, A., Pöschke, O., Müller-Esterl, W., \& JahnenDechent, W. (1996). The serum protein alpha2-HS glycoprotein/fetuin inhibits apatite formation in vitro and in mineralizing calvaria cells. A possible role in mineralization and calcium homeostasis. The Journal OfBiological Chemistry, 271(34), 20789-20796.
Schultes, B., Frick, J., Ernst, B., Stefan, N., \& Fritsche, A. (2010). The Effect of 6Weeks of Aerobic Exercise Training on Serum Fetuin-Alevels in Non-Diabetic Obese Women. Experimental and Clinical Endocrinology \&amp; Diabetes, 118(10), 754-756. doi:10.1055/s-0030-1253418

Simpson, E. R., Merrill, J. C., Hollub, A. J., Graham-Lorence, S., \& Mendelson, C. R. (1989). Regulation of Estrogen Biosynthesis by Human Adipose Cells. Endocrine Reviews, 10(2), 136-148. doi:10.1210/edrv-10-2-136

Smith, E. R., Ford, M. L., Tomlinson, L. A., Rocks, B. F., Rajkumar, C., \& Holt, S. G. (2010). Poor agreement between commercial ELISAs for plasma fetuinA: An effect of protein glycosylation? Clinica Chimica Acta; International Journal Of Clinical Chemistry, 411(17-18), 1367-1370. doi:10.1016/ j.cca.2010.04.020

Spark, M. J., \& Willis, J. (2012). Systematic review of progesterone use by midlife and menopausal women. Maturitas, 72(3), 192-202. doi:10.1016/ j.maturitas.2012.03.015

Srinivas, P. R., Deutsch, D. D., Mathews, S. T., Goustin, A. S., Leon, M. A., \& Grunberger, G (1996). Recombinant human alpha 2-HS glycoprotein inhibits insulin-stimulated mitogenic pathway without affecting metabolic signalling in Chinese hamster ovary cells overexpressing the human insulin receptor. Cellular Signalling, 8(8), 567-573.

Stefan, N., Fritsche, A., Weikert, C., Boeing, H., Joost, H.-G., Häring, H.-U., \& Schulze, M. B. (2008). Plasma fetuin-A levels and the risk of type 2 diabetes. Diabetes, 57(10), 2762-2767. doi:10.2337/db08-0538

Stefan, N., Hennige, A. M., Staiger, H., Machann, J., Schick, F., Kröber, S. M., .. . Häring, H.-U. (2006). Alpha2-Heremans-Schmid glycoprotein/fetuin-A is associated with insulin resistance and fat accumulation in the liver in humans. Diabetes Care, 29(4), 853-857.

Stout, R. W.(1990). Insulin and atheroma. 20-yr perspective. Diabetes Care, 13(6), 631-654.

Sutton-Tyrrell, K., Wildman, R. P., Matthews, K. A., Chae, C., Lasley, B. L. Brockwell, S., ... Torréns, J. I. (2005). Sex Hormone-Binding Globulin and the Free Androgen Index Are Related to Cardiovascular Risk Factors in Multiethnic Premenopausal and Perimenopausal Women Enrolled in the Study of Women Across the Nation (SWAN). Circulation, 111(10), 1242-1249. doi:10.1161/01.CIR.0000157697.54255.CE

Tchernof,A., Calles-Escandon, J., Sites, C. K., \& Poehlman, E.T.(1998). Menopause, central body fatness, and insulin resistance: effects of hormone-replacement therapy. Coronary Artery Disease, 9(8), 503-511.

Tchernof, A., Toth, M. J., \& Poehlman, E. T. (1999). Sex hormone-binding globulin levels in middle-aged premenopausal women. Associations with visceral obesity and metabolic profile. Diabetes Care, 22(11), 1875-1881.

Vaccarino, V., Badimon, L., Corti, R., Wit, C. de, Dorobantu, M., Hall, A., .. Bugiardini, R.(2011). Ischaemicheart disease in women: are there sex differences in pathophysiology and risk factors? Position Paper from the Working Group on Coronary Pathophysiology and Microcirculation of the European Society of Cardiology. Cardiovascular Research, 90(1), 9-17. doi:10.1093/cvr/cvq394

Weikert, C., Stefan, N., Schulze, M. B., Pischon, T., Berger, K., Joost, H.-G, ... Fritsche,A. (2008). Plasma fetuin-a levels and the risk of myocardial infarction and ischemic stroke. Circulation, 118(24), 2555-2562. doi:10.1161/ CIRCULATIONAHA.108.814418

Williams, J. K., Adams, M. R., \& Klopfenstein, H. S. (1990). Estrogen modulates responses of atherosclerotic coronary arteries. Circulation, 81(5), 1680-1687.

Williams, M. J., Hunter, G. R., Kekes-Szabo, T., Trueth, M. S., Snyder, S., Berland, L., \& Blaudeau, T. (1996). Intra-abdominal adipose tissue cut-points related to elevated cardiovascular risk in women. International Journal Of Obesity And Related Metabolic Disorders: Journal Of The International Association For The Study OfObesity, 20(7), 613-617.

Yang, S. J., Hong, H. C., Choi, H. Y., Yoo, H. J., Cho, G J., Hwang, T. G., .. Choi, K. M.(2011). Effects of a three-month combined exercise programme on fibroblast growth factor 21 and fetuin-A levels and arterial stiffness in obese women. Clinical Endocrinology, 75(4), 464-469. doi:10.1111/j.13652265.2011.04078.x

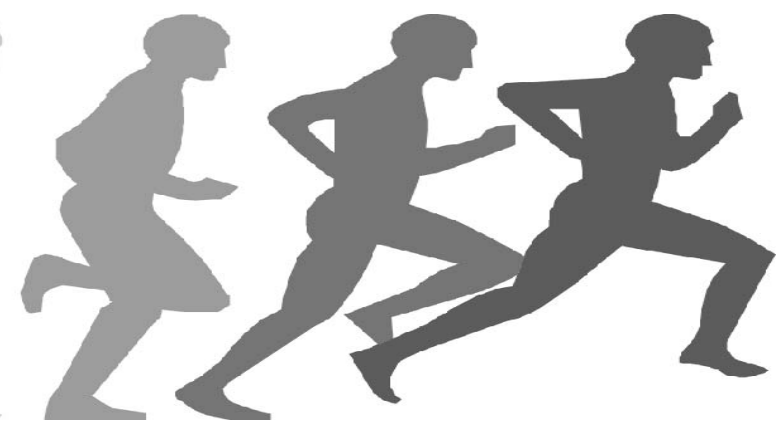

